\title{
Detection of DNA hypermethylation in sera of patients with Crohn's disease
}

\author{
JIN-HAN BAE ${ }^{1}$, JONGHA PARK ${ }^{2}$, KWANG MO YANG ${ }^{1}$, TAE-OH KIM $^{2 *}$, JOO MI YI ${ }^{2 *}$; \\ IBD Study Group of the Korean Association for the Study of Intestinal Diseases (KASID) \\ ${ }^{1}$ Research Center, Dongnam Institute of Radiological and Medical Sciences (DIRAMS); \\ ${ }^{2}$ Department of Internal Medicine, Inje University Haeundae Paik Hospital, Busan, Republic of Korea
}

Received June 25, 2013; Accepted November 11, 2013

DOI: $10.3892 / \mathrm{mmr} .2013 .1840$

\begin{abstract}
Mounting evidence suggests that inflammatory bowel disease (IBD) is caused by genetic predisposition of various genes as well as an abnormal interaction with environmental factors, resulting in epigenetic alterations. It has become evident that epigenetic factors play a significant contributory role during disease development. Additionally, DNA methylation has been reported to be correlated with the development of IBD. In the present study, we examined the role of DNA hypermethylation in Crohn's disease (CD) patients. The transcription elongation regulator 1-like (TCERG1L) gene, which has been previously reported to be highly frequently methylated in colon tumors was selected as a candidate for the early detection of biomarkers for colon cancer patients. DNA methylation of TCERG1L in 101 serum samples of CD patients was examined. Results of conventional MSP analysis revealed high methylation [57\% (58/101)] of serum samples in CD patients. The DNA methylation pattern of TCEEGIL was confirmed using bisulfate sequencing analysis. The results of the present study suggest that using regular colonoscopic surveillance sensitive DNA methylation markers may detect serum samples of CD patients, leading to reduced risk or prevention of the progression of advanced stages of disease.
\end{abstract}

Correspondence to: Dr Joo Mi Yi, Research Center, Dongnam Institute of Radiological and Medical Sciences (DIRAMS), Jwadong-gil 40, Jangan-eup, Gijang-gun, Busan 619-953, Republic of Korea

E-mail: jmyi@dirams.re.kr

Dr Tae-Oh Kim, Department of Internal Medicine, Inje University Haeundae Paik Hospital, 875 Haeundae-ro, Haeundae-gu, Busan 612-896, Republic of Korea

E-mail: kto0440@paik.ac.kr

*Contributed equally

Key words: DNA methylation, Crohn's disease, hypermethylation

\section{Introduction}

Inflammatory bowel disease (IBD) is a heterogeneous disease characterized by Crohn's disease (CD) and ulcerative colitis (UC). CD most commonly involves the ileum and colon but can affect any region of the abominal area. UC often involves the rectum, and inflammation may extend as far as the cecum in a contiguous pattern (1). Strong familial aggregation, twin studies and established genetic associations have demonstrated the importance of genetics in IBD pathogenesis (2-4). Currently, $>32$ susceptibility loci have been identified for IBD (5-10). However, all these genetic risk factors only account for $20 \%$ of the genetic risk (11), suggesting that other factors, including possible epigenetic factors, are involved in IBD pathogenesis (12). However, the epigenetic aspect of IBD has not been systemized.

DNA methylation is an important epigenetic alteration that is involved in the development and differentiation of diseases (13). The aberrant DNA methylation involves promoter $\mathrm{CpG}$ island methylation and silenced genes in cancer such as tumor suppressor genes (13). The involvement of DNA methylation in various types of cancer and several other human diseases including IBD has been widely investigated (14). Abnormal DNA methylation has been observed in UC patients in the estrogen receptor (ER), p14 ${ }^{A R F}$, and E-cadherin gene and emerging evidence suggests the involvement of epigenetic factors in the regulation of gene activity as a factors in the pathogenesis of IBD $(15,16)$. Additionally, it has been previously reported that $\mathrm{CpG}$ islands in the promoter region of transcription elongation regulator 1-like (TCERG1L) gene are highly methylated, not only in colon cancer patient tissues, particularly those obtained from early stage of colon cancer patients (17), but also in patients with UC (18). However, little is known regarding DNA methylation in patients with CD.

Analysis of DNA methylation is leading to a new generation of cancer biomarkers (19). It was previously demonstrated that abnormally high DNA concentrations can also be detected in the serum, plasma, and urine of cancer patients $(20,21)$. Aberrantly methylated DNA sequences occur frequently in tumors and have been detected in the circulation of cancer patients by methylation-specific PCR (MSP) $(22,23)$. Findings of those studies demonstrated that the presence of aberrantly methylated gene DNA in serum 
is highly correlated with the occurrence of various types of cancer as well as inflammatory disease such as that present in patients with CD. In the present study, the methylation status of TCERGIL gene in the serum samples of CD patients was measured. In addition, detection of the promoter DNA hypermethylation of TCERGIL in the serum samples of CD patients was examined. The results obtained show that the methylation status of TCERG1L gene in the serum of CD patients has the potential to become a risk marker for the progression of severe disease.

\section{Materials and methods}

Patients and samples. Serum DNA samples were obtained from CD patients according to the guidelines of the IBD Study Group of the Korean Association for the Study of Intestinal Diseases (KASID). Of the 101 subjects, 62 were male and 39 female, yielding a male:female ratio of 1.6:1. The median age at diagnosis of CD was 24 years (range, 12-66). $\mathrm{CD}$ was diagnosed on the basis of conventional clinical, radiologic, endoscopic, and histopathologic criteria (24-26). Briefly, patients were diagnosed with CD if they met at least two of the following criteria: i) a history of abdominal pain, weight loss, malaise, diarrhea, and/or rectal bleeding; ii) endoscopic findings of mucosal cobblestoning, linear ulceration, skip areas, or perianal disease; iii) radiologic findings of stricture, fistula, mucosal cobblestoning, or ulceration; iv) macroscopic appearance of bowel wall induration, mesenteric lymphadenopathy, and 'creeping fat' on laparotomy; and v) pathologic findings of transmural inflammation and/or epithelioid granulomas. At the time of diagnosis, 26 patients (25.7\%) had disease located in the small bowel alone (L1), $12(11.9 \%)$ had disease in the colon alone (L2), and $63(62.4 \%)$ had disease in the small bowel and colon (L3). Disease behavior at diagnosis was inflammatory (B1) in 63 patients (62.4\%), stricturing (B2) in 27 (26.7\%), and penetrating (B3) in $11(10.9 \%)$. Clinical characteristics of these patients are shown in Table I.

Cell culture and treatment. Colorectal cell lines (HCT116, RKO, HT29, SW480, DLD1, COLO 320, Lovo, and Caco-2) were obtained from the American Type Culture Collection (ATCC, Manassas, VA, USA) and cultured in an appropriate medium and under conditions described by the ATCC. Media were obtained from Invitrogen Life Technologies (Carlsbad, CA, USA), supplemented with $10 \%$ fetal bovine serum (Gemini Bio-Products, West Sacramento, CA, USA) and 1\% penicillin/streptomycin (Invitrogen Life Technologies).

DNA extraction and methylation analyses. DNA was extracted following a standard phenol-chloroform extraction protocol. Bisulfite modification of DNA was performed using the EZ DNA Methylation kit ${ }^{\mathrm{TM}}$ (Zymo Research, Irvine, CA, USA) as per the manufacturer's instructions. MSP was carried out in a $25-\mu 1$ reaction containing $10 \mathrm{X}$ MSP buffer, $10 \mathrm{mM}$ dNTPs, $10 \mathrm{pmol}$ of each of the methylated or unmethylated primers, 1 unit of JumpStart ${ }^{\mathrm{TM}}$ REDTaq $^{\circledR}$ DNA polymerase (Sigma, St. Louis, MO, USA) and $4 \mu \mathrm{l}$ of bisulfite-treated DNA. Amplification cycles were as follows: 1 cycle of $95^{\circ} \mathrm{C}$ for $5 \mathrm{~min}$ followed by 35 cycles of $95^{\circ} \mathrm{C}$ for
Table I. Characteristics of samples of patient with CD.

\begin{tabular}{lc}
\hline Characteristics & Values \\
\hline Blood samples (total n=101) & \\
Age (years) & $24(12-66)$ \\
Median (range) & \\
Gender, $\mathrm{n}(\%)$ & $62(61.3)$ \\
Male & $39(38.6)$ \\
Female & \\
Disease location at diagnosis, $\mathrm{n}(\%)$ & $26(25.7)$ \\
Small bowel alone & $12(11.9)$ \\
Colon alone & $63(62.4)$ \\
Small bowel and colon & \\
Disease behavior at diagnosis, $\mathrm{n}(\%)$ & $63(62.4)$ \\
Inflammatory (B1) & $27(26.7)$ \\
Stricturing (B2) & $11(10.9)$ \\
Penetrating (B3) & \\
Tissue samples (total n=7) & \\
Age (years) & $21(14.2)$ \\
Median & \\
Gender, n (\%) & $3(42.9)$ \\
Male & $1(14.2)$ \\
Female & \\
Disease location at diagnosis, $\mathrm{n}(\%)$ & \\
Small bowel alone & \\
Colon alone & \\
Small bowel and colon & \\
Disease behavior at diagnosis, $\mathrm{n}(\%)$ & \\
Inflammatory (B1) & \\
Stricturing (B2) & \\
Penetrating (B3) & \\
\hline
\end{tabular}

CD, Crohn's disease.

$30 \mathrm{sec}, 60^{\circ} \mathrm{C}$ for $30 \mathrm{sec}, 72^{\circ} \mathrm{C}$ for $30 \mathrm{sec}$, and a final extension step of $72^{\circ} \mathrm{C}$ for $5 \mathrm{~min}$. In vitro-methylated DNA (IVD) was used as a positive control for MSP. A total of $10 \mu \mathrm{l}$ of each amplification reaction was loaded and run on $2 \%$ agarose gel containing GelStar ${ }^{\mathrm{TM}}$ Nucleic Acid Gel Stain (Lonza, Basel, Switzerland) and visualized under ultraviolet illumination. Primers for MSP analysis were previously reported in the study by Yi et al (17).

Quantitative methylation-specific PCR using qPCR. Bisulfite modification of genomic DNA was carried out using the EZ DNA methylation kit (Zymo Research). For quantitative real-time analyses, the Maxima SYBR-Green qPCR kit (Fermentas, Seoul, Korea) was used and the amplification conditions consisted of an initial 10-min denaturation step at $95^{\circ} \mathrm{C}$, followed by 40 cycles of denaturation at $95^{\circ} \mathrm{C}$ for $15 \mathrm{sec}$ and annealing and extension for 30 and $60 \mathrm{sec}$, respectively. A CFX96 real-time PCR detection system (Bio-Rad Laboratories, Inc., Hercules, CA, USA) and for quantification 
the comparative cycle threshold $(\mathrm{Ct})$ method were used, normalizing the $\mathrm{Ct}$ values for the indicated gene to the $\mathrm{Ct}$ values of unmethylated reaction relative to a methylated reaction sample.

Bisulfite sequencing analysis. Genomic DNA (1 $\mu \mathrm{g})$ from each sample was converted by bisulfite using the EZ DNA methylation kit (Zymo Research) following the manufacturer's instructions. PCR conditions and primer sequences are available subsequent to request. The PCR amplicons were gel-purified and subcloned into a pCRII-TOPO vector (Invitrogen Life Technologies). Clones were randomly selected and sequenced on an ABI3730xl DNA analyzer to ascertain the methylation patterns of each locus. The primers for bisulfite sequencing analysis have been previously reported by Yi et al (17).

Statistical analysis. Statistical analysis was performed using the STATA 9.2 software package (Stata Corporation, College Station, TX, USA). Most analyses were conducting using a t-test, while continuous variables were analyzed using the Mann-Whitney U test. $\mathrm{P}<0.05$ was considered statistically significant.

\section{Results and Discussion}

Detection of DNA promoter hypermethylation of TCERGIL gene in sera of patients with $C D$. Understanding the causes and molecular mechanisms of CD and UC, the two forms of idiopathic IBD, is a major challenge in gastroenterology research. Although significant effort has been made to identify genetic and environmental factors that may increase the risk of IBD, little is known IBD-specific factors $(8,27)$. Mounting evidence supports the theory that IBD is caused by a complex interplay between genetic predispositions of various genes, combined with an abnormal interaction with environmental factors. Thus, it appears that epigenetic factors significantly contribute to the pathogenesis of disease.

Recently, studies have focused on two separate DNA hypermethylation biomarker candidate genes in patients with colon cancer and UC $(17,18)$. In the present study, the hypothesis that extremely sensitive DNA methylation marker candidates in colon cancer are capable of detecting high-risk inflammatory diseases such as UC and CD in patients, led to DNA methylation analysis in the serum samples of CD patients using TCERGIL gene promoter region.

The TCERG1L gene which is located on chromosome 10, has exhibited frequent cancer-specific methylation in microarray-based approaches (28). TCERGIL is potentially involved in the elongation-related factors in HeLa nuclear extracts (29), however, this remains to be elucidated. CpG islands of the TCERGIL gene promoter region are known to be frequently methylated in the early stage of colon cancer (17), thus genomic DNA from the sera of patients with CD $(n=101)$ was extracted. First, we assessed the methylation level of TCERG1L gene promoter region in 101 serum samples of patients with CD by MSP analysis. Conventional MSP analysis was performed successfully in the majority of samples. Fig. 1 shows the frequency of hypermethylation for the TCERGIL gene promoter region in the sera of patients

\section{TCERG1L}

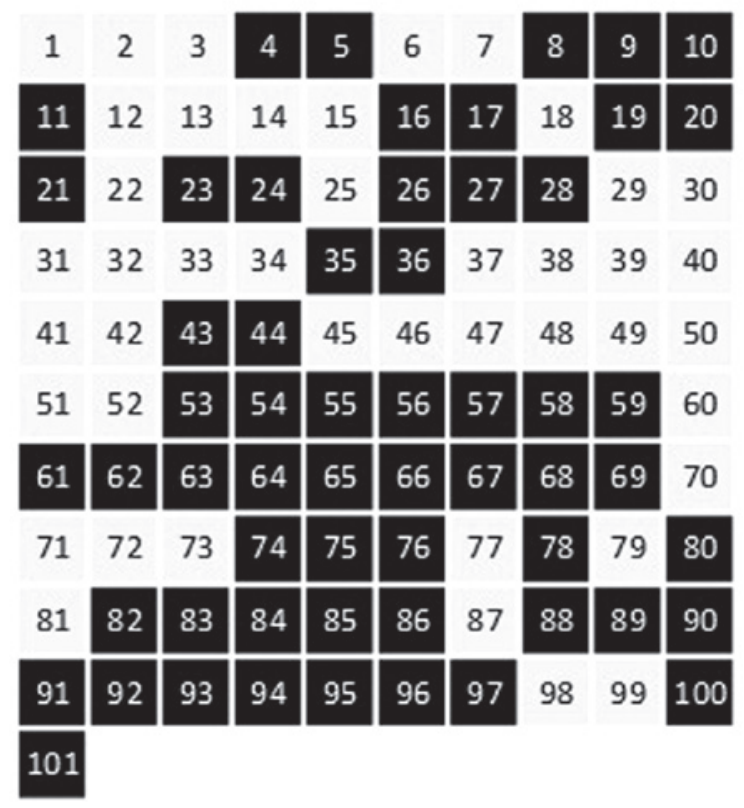

Figure 1. Methylation analysis of transcription elongation regulator 1-like (TCERG1L) gene in 101 serum samples of patients with Crohn's disease (CD). Each square and numbers show single CD patient serum samples. White squares show unmethylated samples. Black squares show methylated samples.

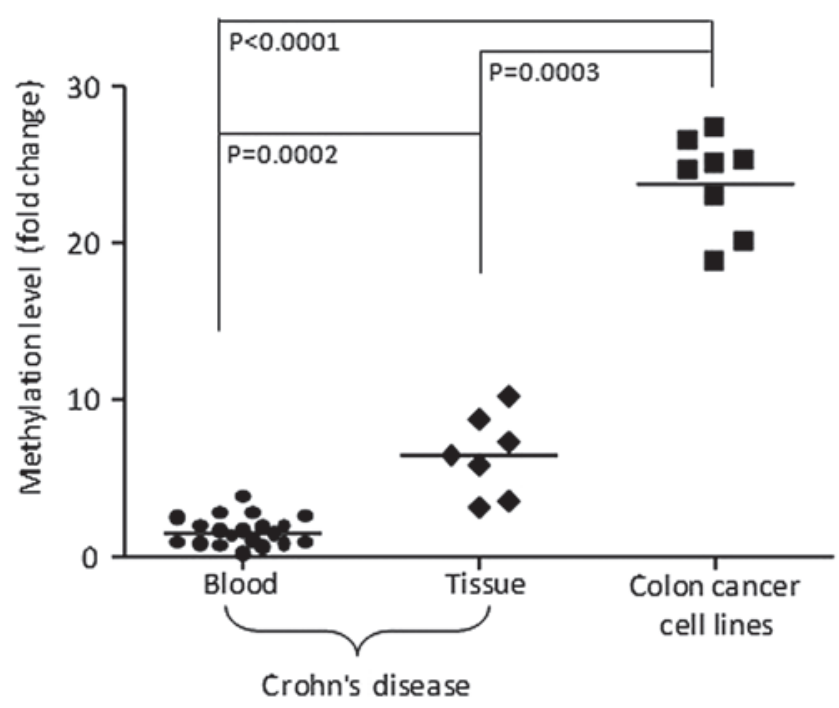

Figure 2. Quantitative MSP (qMSP) analysis for transcription elongation regulator 1-like (TCERG1L) gene in Crohn's disease (CD) patient serum sample, CD patient tissue, and colon cancer cell lines. Each dot indicates the methylation levels of each tested samples $(n=20$ for serum samples of CD patients, $n=7$ for tissue samples of $C D$ patients, $n=8$ for colon cancer cell lines) by real-time qMSP. P-values $<0.05$ were considered significant.

with CD, and $58(57 \%)$ of the 101 samples were found to be methylated. We also tested FBN2 gene in the serum samples of patients with $\mathrm{CD}$ which is known to be frequently methylated in the early stages of colon cancer. However, no methylation was detected in the samples tested in the present study (data not shown). Previously, we demonstrated that 


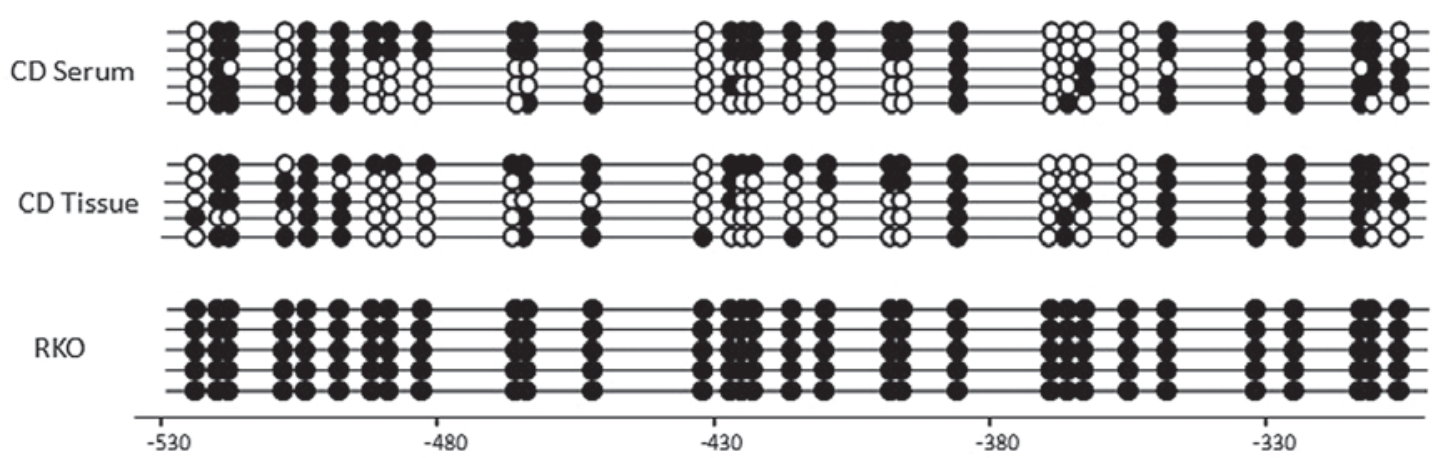

Figure 3. Representative bisulfite sequencing results for transcription elongation regulator 1-like (TCERGIL) gene in Crohn's disease (CD) patient serum (patient \#11), tissue (patient \#3), and RKO colon cancer cell line. The location of each CpG site relative to the transcription start site is shown at the bottom of the panels. Open and filled circles indicate methylation and no methylation, respectively.

the DNA hypermethylation of TCERGIL and FBN2 was detected in UC patient tissue samples (18). However, in the present study, we only detected the DNA methylation of the TCERGIL gene in serum samples of patients with CD. The results suggest that TCERGIL gene is extremely sensitive as a methylation marker in the detection of early stages of cancer as well as inflammatory diseases such as IBD. In addition, it was suggested that there may be differences in DNA methylation signatures at the gene level between $\mathrm{UC}$ and CD patients. Therefore, genome-wide methylation analyses are necessary to identify differential methylation levels between UC and $\mathrm{CD}$ in future.

TCERGIL methylationanalysis in patients with CD.TCERGIL was previously reported to be completely methylated (17). Fig. 2 shows the relative TCERGIL hypermethylation status in the serum samples $(\mathrm{n}=20)$ and tissue $(\mathrm{n}=7)$ of patients with CD compared with colon cancer cell lines $(n=8)$ using qMSP. In terms of methylation quantification, the methylation level of TCERGIL gene in colon cancer cell lines was relatively higher than that of patients with $\mathrm{CD}$, thus the methylation level in cancer is denser than that in inflammatory disease. We also compared the methylation level of TCERGIL between tissue from biopsy and blood samples. The methylation level in tissue samples with $C D$ was 2- to 4-fold higher than that in blood samples. We detected TCERGIL methylation in blood and tissue samples of patients with $\mathrm{CD}$ by conventional MSP, however, quantification of the methylation level distinguished between cancer and CD. P-values were statistically significant between $\mathrm{CD}$ and colon cancer cell lines (blood, $\mathrm{P}<0.0001$; tissue, $\mathrm{P}=0.0003$ ) as well as blood and tissue with $\mathrm{CD}(\mathrm{P}=0.0002)$. Our data suggest that DNA hypermethylation of TCERG1L gene is sensitive enough to detect patient blood or tissue samples with $\mathrm{CD}$. Limited clinical information of the CD patients in the present study was obtained. Thus, additional studies are required to investigate the correlation between clinical data of $\mathrm{CD}$ patients such as duration and methylation level.

The methylation pattern in the $\mathrm{CpG}$ islands of the promoter region of TCERG1L gene by bisulfite sequencing analysis was also confirmed (Fig. 3). The bisulfate sequencing region amplified has $31 \mathrm{CpG}$ sites. The TCERGIL gene was previously reported to have a dense $\mathrm{CpG}$ methylation pattern in
CRC tumors (17). In this study, we found that TCERGIL gene showed a dense $\mathrm{CpG}$ methylation pattern in the blood (patient \#11) and tissue (patient \#3) of CD patients at 51\% (methylation site per $\mathrm{CpG}$ site) compared with complete methylation $(100 \%)$ in RKO colon cancer cells. Our results suggest that TCERGIL gene is densely methylated in CD patients, and the DNA methylation of TCERGIL is sensitive enough to detect inflammatory diseases such as CD. However, certain limitations of the present study should be considered. A lack of control samples with $\mathrm{CD}$ did not yield specificity with TCERGIL gene methylation. Additionally, there was a lack of clinical information for $\mathrm{CD}$ samples including disease duration in the present study; thus we were not able to compare results of various analyses associated with DNA methylation of TCERGIL. Therefore, additional studies are needed to define the use of DNA methylation markers with clinical data of CD patients, including control samples.

In conclusion, we assessed the promoter DNA methylation pattern of TCERGIL gene in the blood samples of CD patients. We were able to detect TCERGIL gene promoter methylation in 57\% of patient blood samples with CD by conventional MSP analysis. The DNA methylation status of TCERGIL in $\mathrm{CD}$ patient tissue and blood samples was also confirmed by bisulfite sequencing analysis. A comparison of the quantitative methylation levels among CD patient tissue, blood and colon cancer cell lines was conducted. Results showed the methylation level of TCERGIL in colon cancer cell lines to be significantly higher than that in CD patient blood and tissue samples. Additionally, results of this study have demonstrated that methylation of TCERGIL is sensitive enough to detect inflammatory disease in tissue and blood samples of patients with $\mathrm{CD}$. Thus, sensitive methylation markers may be useful in the detection of inflammatory diseases which have the potential risk of progression of severe disease in $\mathrm{CD}$ patients.

\section{Acknowledgements}

This study was supported by the National R\&D program (50596-2014) through the Dongnam Institute of Radiological and Medical Sciences (DIRAMS) funded by the Korean Ministry of Education, Science and Technology. This study was also supported by a fund (2013-E63004-00) by Research of Korea Centers for Disease Control and Prevention. 


\section{References}

1. Podolsky DK: Inflammatory bowel disease. N Engl J Med 347: 417-429, 2002

2. Halfvarson J, Bodin L, Tysk C, Lindberg E and Järnerot G: Inflammatory bowel disease in a Swedish twin cohort: a long-term follow-up of concordance and clinical characteristics. Gastroenterology 124: 1767-1773, 2003.

3. Thompson NP, Driscoll R, Pounder RE and Wakefield AJ: Genetics versus environment in inflammatory bowel disease: results of a British twin study. BMJ 312: 95-96, 1996.

4. Tysk C, Lindberg E, Järnerot G and Flodérus-Myrhed B: Ulcerative colitis and Crohn's disease in an unselected population of monozygotic and dizygotic twins. A study of heritability and the influence of smoking. Gut 29: 990-996, 1988.

5. Yamazaki K, McGovern D, Ragoussis J, Paolucci M, Butler H, Jewell D, Cardon L, Takazoe M, Tanaka T, Ichimori T, Saito S, Sekine A, et al: Single nucleotide polymorphisms in TNFSF15 confer susceptibility to Crohn's disease. Hum Mol Genet 14 3499-3506, 2005.

6. Duerr RH, Taylor KD, Brant SR, Rioux JD, Silverberg MS, Daly MJ, Steinhart AH, Abraham C, Regueiro M, Griffiths A, Dassopoulos T, Bitton A, et al: A genome-wide association study identifies $I L 23 R$ as an inflammatory bowel disease gene. Science 314: 1461-1463, 2006.

7. Hampe J, Franke A, Rosenstiel P, Till A, Teuber M, Huse K, Albrecht M, Mayr G, De La Vega FM, Briggs J, Günther S, Prescott NJ, et al: A genome-wide association scan of nonsynonymous SNPs identifies a susceptibility variant for Crohn disease in ATG16L1. Nat Genet 39: 207-211, 2007.

8. Rioux JD, Xavier RJ, Taylor KD, Silverberg MS, Goyette P, Huett A, Green T, Kuballa P, Barmada MM, Datta LW Shugart YY, Griffiths AM, et al: Genome-wide association study identifies new susceptibility loci for Crohn disease and implicates autophagy in disease pathogenesis. Nat Genet 39: 596-604, 2007.

9. Wellcome Trust Case Control Consortium: Genome-wide association study of 14,000 cases of seven common diseases and 3,000 shared controls. Nature 447: 661-678, 2007.

10. Parkes M, Barrett JC, Prescott NJ, Tremelling M, Anderson CA, Fisher SA, Roberts RG, Nimmo ER, Cummings FR, Soars D, Drummond H, Lees CW, et al: Sequence variants in the autophagy gene IRGM and multiple other replicating loci contribute to Crohn's disease susceptibility. Nat Genet 39: 830-832, 2007

11. Barrett JC, Hansoul S, Nicolae DL, Cho JH, Duerr RH, Rioux JD, Brant SR, Silverberg MS, Taylor KD, Barmada MM, Bitton A, Dassopoulos T, et al: Genome-wide association defines more than 30 distinct susceptibility loci for Crohn's disease. Nat Genet 40: 955-962,2008.

12. Petronis A and Petroniene R: Epigenetics of inflammatory bowel disease. Gut 47: 302-306, 2000.

13. Jones PA and Baylin SB: The epigenomics of cancer. Cell 128 : 683-692, 2007

14. Robertson KD: DNA methylation and human disease. Nat Rev Genet 6: 597-610, 2005.

15. Maeda $\mathrm{O}$, Ando $\mathrm{T}$, Watanabe $\mathrm{O}$, Ishiguro $\mathrm{K}$, Ohmiya $\mathrm{N}$, Niwa Y and Goto H: DNA hypermethylation in colorectal neoplasms and inflammatory bowel disease: a mini review. Inflammopharmacology 14: 204-206, 2006.
16. Tahara T, Shibata T, Nakamura M, Yamashita H, Yoshioka D, Okubo M, Maruyama N, Kamano T, Kamiya Y, Nakagawa Y, Fujita H, Nagasaka M, et al: Effect of MDR1 gene promoter methylation in patients with ulcerative colitis. Int J Mol Med 23: 521-527, 2009.

17. Yi JM, Dhir M, Guzzetta AA, Iacobuzio-Donahue CA, Heo K, Yang KM, Suzuki H, Toyota M, Kim HM and Ahuja N: DNA methylation biomarker candidates for early detection of colon cancer. Tumour Biol 33: 363-372, 2012.

18. Kim TO, Park J, Kang MJ, Lee SH, Jee SR, Ryu DY, Yang K and Yi JM: DNA hypermethylation of a selective gene panel as a risk marker for colon cancer in patients with ulcerative colitis. Int J Mol Med 31: 1255-1261, 2013.

19. Laird PW: The power and the promise of DNA methylation markers. Nat Rev Cancer 3: 253-266, 2003.

20. Widschwendter $M$ and Menon U: Circulating methylated DNA: a new generation of tumor markers. Clin Cancer Res 12: 7205-7208, 2006.

21. Wallner M, Herbst A, Behrens A, Crispin A, Stieber P, Göke B, Lamerz R and Kolligs FT: Methylation of serum DNA is an independent prognostic marker in colorectal cancer. Clin Cancer Res 12: 7347-7352, 2006.

22. Esteller M, Sanchez-Cespedes M, Rosell R, Sidransky D, Baylin SB and Herman JG: Detection of aberrant promoter hypermethylation of tumor suppressor genes in serum DNA from non-small cell lung cancer patients. Cancer Res 59: 67-70, 1999.

23. deVos T, Tetzner R, Model F, Weiss G, Schuster M, Distler J, Steiger KV, Grützmann R, Pilarsky C, Habermann JK, Fleshner PR, Oubre BM, et al: Circulating methylated SEPT9 DNA in plasma is a biomarker for colorectal cancer. Clin Chem 55: 1337-1346, 2009.

24. Yang SK, Yun S, Kim JH, Park JY, Kim HY, Kim YH, Chang DK, Kim JS, Song IS, Park JB, Park ER, Kim KJ, et al: Epidemiology of inflammatory bowel disease in the Songpa-Kangdong district, Seoul, Korea, 1986-2005: a KASID study. Inflamm Bowel Dis 14: 542-549, 2008.

25. Loftus EV Jr, Silverstein MD, Sandborn WJ, Tremaine WJ, Harmsen WS and Zinsmeister AR: Crohn's disease in Olmsted County, Minnesota, 1940-1993: incidence, prevalence, and survival. Gastroenterology 114: 1161-1168, 1998.

26. Lee YJ, Yang SK, Byeon JS, Myung SJ, Chang HS, Hong SS, Kim KJ, Lee GH, Jung HY, Hong WS, Kim JH, Min YI, et al: Analysis of colonoscopic findings in the differential diagnosis between intestinal tuberculosis and Crohn's disease. Endoscopy 38: 592-597, 2006.

27. Brentnall TA, Crispin DA, Rabinovitch PS, Haggitt RC, Rubin CE, Stevens AC and Burmer GC: Mutations in the p53 gene: an early marker of neoplastic progression in ulcerative colitis. Gastroenterology 107: 369-378, 1994

28. Schuebel KE, Chen W, Cope L, Glöckner SC, Suzuki H, Yi JM, Chan TA, Van Neste L, Van Criekinge W, van den Bosch S, van Engeland M, Ting AH, et al: Comparing the DNA hypermethylome with gene mutations in human colorectal cancer PLoS Genet 3: 1709-1723, 2007.

29. Sánchez-Alvarez M, Goldstrohm AC, Garcia-Blanco MA and Suñé C: Human transcription elongation factor CA150 localizes to splicing factor-rich nuclear speckles and assembles transcription and splicing components into complexes through its amino and carboxyl regions. Mol Cell Biol 26: 4998-5014, 2006. 